Brit. J. vener. Dis. (1966), 42, 96.

\title{
SACRO-ILIAC CHANGES AND URINARY INFECTION IN PATIENTS WITH SPINAL CORD INJURIES*
}

BY

\author{
MIRIAM LIBERSON AND NIKOLA MIHALDZIC
}

From the Department of Radiology, Veterans Administratıon West Side Hospital, Chicago, Illinois, and the Spinal Cord Injuries Service, Veterans Administration Hospital, Hines, Illinois

The presence of erosive and ankylosing changes in the sacro-iliac joints in paraplegics has been described by Abramson and Kamberg (1949) and by Romanus (1953). The relationship between such changes and urinary tract infection has been implicated by Grainger and Nicol (1959), Alexander (1960), and Romanus (1953) with various degrees of emphasis in a variety of conditions; Reiter's syndrome is the most consistently quoted (Oates, 1959; Good, 1962; Poske, Montgomery, Pilz, Barton, and Foxworthy, 1961).

The fact that urinary infection is practically universal in spinal cord and cauda equina injuries makes the evaluation of correlation between such an infection and sacro-iliac changes difficult. In the present study a large number of quadriplegics and paraplegics with different levels of cord involvement as well as various degrees of urinary infection were examined.

In some of these patients severe urinary infection was demonstrated by persistent morphological changes of the pelvicalyceal structures demonstrated on excretory urograms. The effects of such abnormalities upon the development of sacro-iliac lesions were evaluated.

\section{Patients Studied}

Originally the group consisted of 100 consecutively hospitalized patients. Thirteen cases of lumbar lesions were added at random to this series as the number of such lesions was too small in the original group of patients. Follow-up varied from 1 to 19 years. The distribution according to the level of cord lesion is represented in Table I.

TABLE I

DISTRIBUTION OF THE PATIENTS ACCORDING TO SITE OF LESION

\begin{tabular}{|c|c|}
\hline Site of Lesion & No. of Cases \\
\hline $\begin{array}{l}\text { Cervical } \\
\text { Dorsal } \\
\text { Lumbar }\end{array}$ & $\begin{array}{l}48 \\
35 \\
30\end{array}$ \\
\hline Total & 113 \\
\hline
\end{tabular}

* Received for publication August 5, 1965.

\section{Criteria of Abnormality}

(a) Skeletal.-Sacro-iliac changes were evaluated exclusively on the basis of $x$-ray findings as the usual clinical manifestations were absent because of sensory loss.

The classical radiological stages of ankylosing spondylitis were accepted as criteria:

(1) Bilateral blurring of joint space and bone sclerosis;

(2) Cortical erosions with pseudo-widening of joint space.

(3) Narrowing of joint space with partial or complete obliteration.

These stages are less clearly defined in paraplegics. The bone sclerosis is less common; asymmetric involvement is not rare. In some cases it may persist indefinitely; in the majority of cases, however, the apparently noninvolved joint later becomes obliterated (Fig. $1 a, b, c$, opposite).

Although the complete obliteration of the sacro-iliac space constitutes the most common final appearance, often the evaluation of loss of joint space is difficult because of the severe osteoporosis which is so frequent below the level of cord lesions. The projection of the sacro-iliac joints on the excretory urograms is not always favourable for such an evaluation.

(b) Excretory Urograms.-Persistent unilateral or bilateral hydronephrosis on serial excretory urograms was considered as a criterion of definite urinary infection.

\section{Findings}

(1) Localization of Spinal Cord Injury and Sacro-iliac Changes.-The distribution of $x$-ray findings according to the site of the spinal cord lesion is illustrated by Table II.

TABLE II

LOCALIZATION OF SPINAL CORD INJURY AND SKELETAL CHANGES

\begin{tabular}{r|c|c|c|c}
\hline \multirow{2}{*}{ Site of Lesion } & \multicolumn{2}{|c|}{$X$ Rays } & & \multirow{2}{*}{$\begin{array}{c}\text { Percentage } \\
\text { Positive }\end{array}$} \\
\cline { 2 - 3 } & Positive & Negative & Total & \\
\hline Cervical & 29 & 19 & 48 & 60 \\
Dorsal & 18 & 17 & 35 & 51 \\
Lumbar & 19 & 11 & 30 & 63 \\
\hline Total & 66 & 47 & 113 & 58 \\
\hline
\end{tabular}



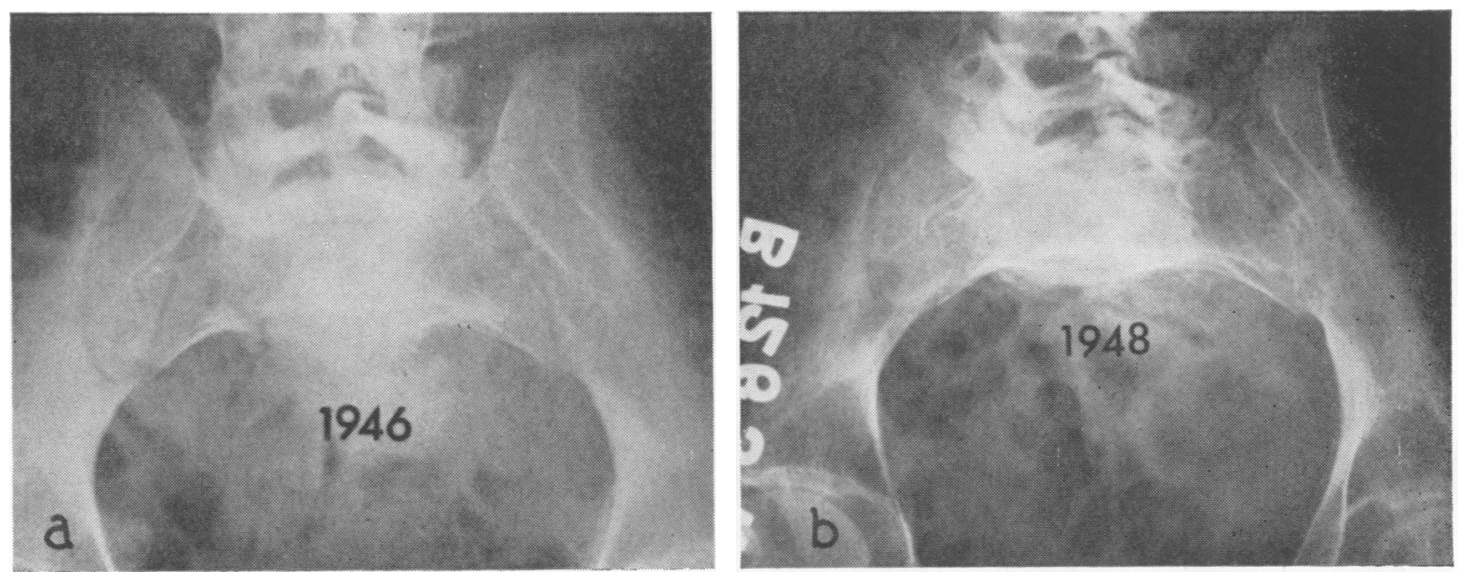

FIG. 1.-Patient aged 21 at time of injury in 1944.

(a) In 1946, the left sacro-iliac is partly obliterated, the right appears normal;

(b) In 1948, the right sacro-iliac remains unchanged, but the left is now completely obliterated;

(c) 19 years after the injury (1963) the joint space appears completely obliterated bilaterally.

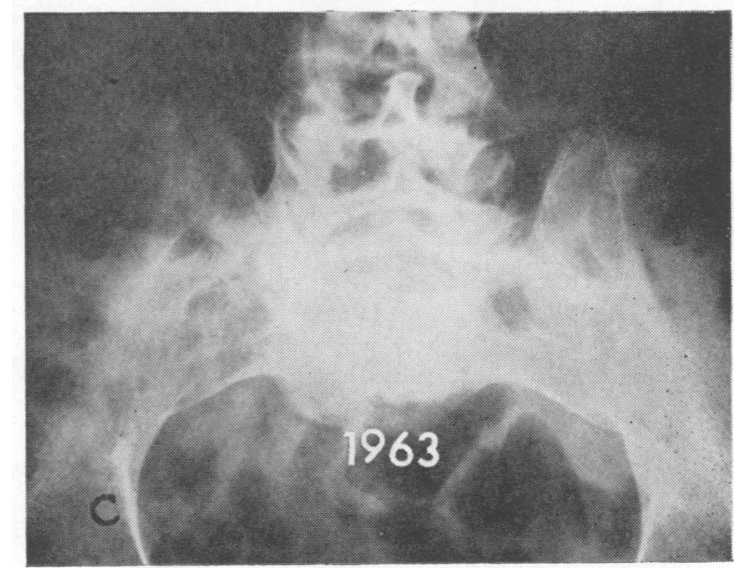

The incidence of positive sacro-iliac changes is very similar in patients with cervical and lumbar lesions, the figure being slightly lower in lesions of the dorsal region.

(2) Effect of Duration of Illness.-In 53 cases with functionally complete trans-section of the cord, the degree of severity of skeletal lesions was evaluated in relation to the duration of illness. It was found that 2 to 3 years after injury there is a sudden increase in the degree of $x$-ray changes; then a slower progression of abnormality takes place during the following 5 years; the lesions appear to be more or less stabilized 7 to 8 years after the injury (Fig. 2).

(3) Relationship between Excretory Urogram Findings and Sacro-iliac Changes. - The incidence of the $x$-ray findings was studied according to the results of the excretory urograms. Of the 113 patients, 99 had serial excretory urograms, in 32 of these patients unilateral or bilateral persistent hydronephrosis was

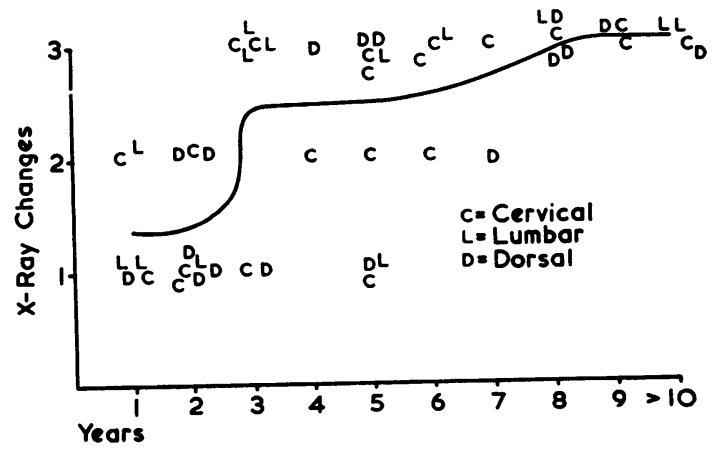

Fig. 2.-Effect of duration of illness on the course of skeletal changes. Characteristic time course shows a sudden increase in the severity of $x$-ray lesions 2 to 3 years after the injury, followed by a slow progression to reach a stabilized stage after 7 to 8 years.

present. The percentage of positive $x$-ray skeletal findings was found to be the same in patients with or without hydronephrosis (Table III, overleaf) 
TABLE III

\begin{tabular}{|c|c|c|c|}
\hline \multirow{2}{*}{ Sacro-iliac Changes } & \multirow{2}{*}{$\begin{array}{c}\text { Total } \\
\text { Patients }\end{array}$} & \multicolumn{2}{|c|}{ I.V.P. } \\
\hline & & Positive & Negative \\
\hline $\begin{array}{l}\text { Present } \\
\text { Absent }\end{array}$ & 66 (58 per cent) & $\begin{array}{c}20 \text { (62 per cent) } \\
12\end{array}$ & 42 (63 per cent) \\
\hline Total & 113 & 32 & 67 \\
\hline
\end{tabular}

\section{(4) Follow-Up Findings}

(a) Incidence of Sacro-iliac Changes.-Table IV compares the incidence of sacro-iliac changes in the whole group with that found in patients with abnormal excretory urograms from another viewpoint. This incidence was computed for all patients as well as for those with a follow-up of at least 5 years. As shown in this Table there is initially no difference between the patients with hydronephrosis and the whole group. After 5 years' follow-up there is some difference.

TABLE IV

HYDRONEPHROSIS AND FOLLOW-UP OF SKELETAL CHANGES

\begin{tabular}{|c|c|c|c|c|c|c|}
\hline \multirow{2}{*}{$\begin{array}{c}\text { Sacro-iliac } \\
\text { Findings }\end{array}$} & \multicolumn{3}{|c|}{ All Patients } & \multicolumn{3}{|c|}{$\begin{array}{l}\text { Patients with a Follow-up } \\
\text { of at least } 5 \text { years }\end{array}$} \\
\hline & $\begin{array}{l}\text { Posi- } \\
\text { tive }\end{array}$ & $\underset{\text { Nive }}{\text { Nega- }}$ & $\begin{array}{l}\text { Percentage } \\
\text { Positive }\end{array}$ & $\begin{array}{c}\text { Posi- } \\
\text { tive }\end{array}$ & $\begin{array}{c}\text { Nega- } \\
\text { tive }\end{array}$ & $\begin{array}{l}\text { Percentage } \\
\text { Positive }\end{array}$ \\
\hline All Patients & 66 & 47 & 58 & 51 & 47 & 52 \\
\hline $\begin{array}{l}\text { Patients with } \\
\text { Hydro- } \\
\text { nephrosis }\end{array}$ & 20 & 12 & 63 & 18 & 7 & 72 \\
\hline
\end{tabular}

(b) Progress of Sacro-iliac Changes.-The progress of the $x$-ray skeletal changes in patients with a complete cervical lesion and negative excretory urograms is illustrated in Fig. 3.

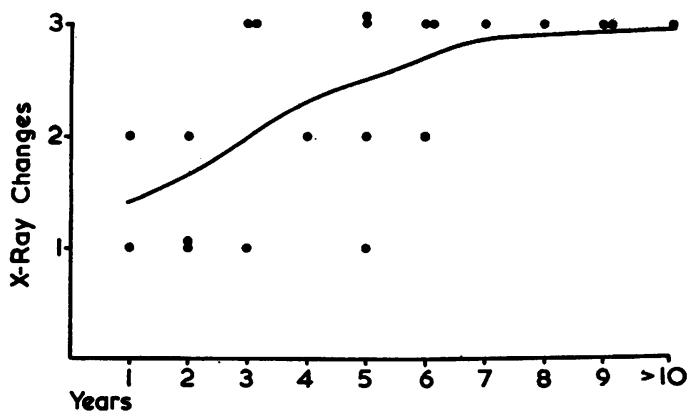

Fig. 3.-Progress of $x$-ray skeletal changes in patients with a complete cervical lesion and negative intravenous pyelogram.

Corresponding data for patients with dorsal and lumbar lesions are shown in Figs 4 and 5 There is no significant difference between these three groups.

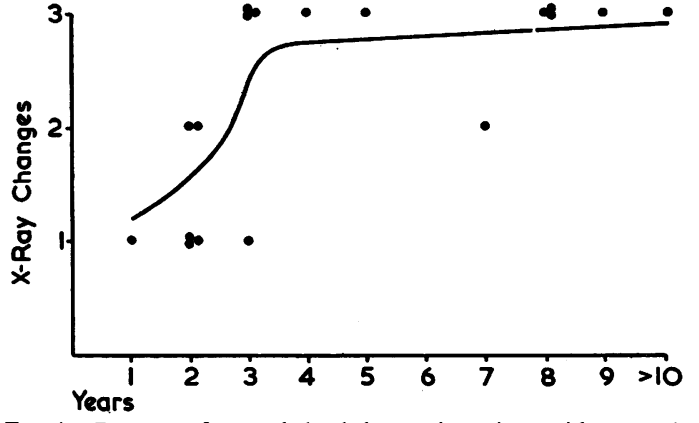

FIG. 4.-Progress of $x$-ray skeletal changes in patients with a complete dorsal lesion and negative intravenous pyelogram.

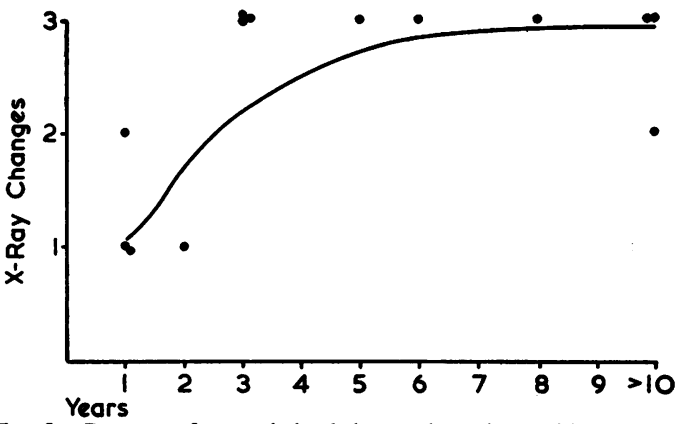

FIG. 5.-Progress of $x$-ray skeletal changes in patients with a complete lumbar lesion and negative intravenous pyelogram.

Similar data for patients with hydronephrosis are represented in Fig. 6. It is suggested that in this group the course of sacro-iliac changes is somewhat more rapid in patients with lumbar lesions.

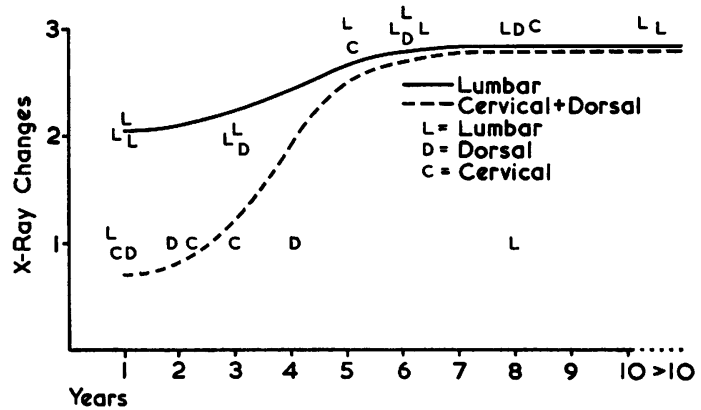

Fig. 6.-Progress of $x$-ray skeletal changes in patients with complete cervical, dorsal, and lumbar lesions and positive intravenous pyelogram. A slightly more rapid course is noted in patients $n$ it lumbar lesions.

\section{Discussion}

This study fails to reveal any evidence that a significant urinary infection per se is a dominant factor in the genesis of skeletal changes. Patients with or without hydronephrosis show the same incidence of sacro-iliac changes. It seems that the 
latter occur independently of the urinary complications of the spinal cord injury and regardless of its level. There is indeed quite a characteristic course of skeletal changes following injury. It is all the more remarkable that some patients with or without hydronephrosis escape this complication. Other factors, possibly genetic, may intervene in such patients. It is interesting to note that similarly a certain percentage of paraplegics, as stated by Liberson (1953), never develop soft tissue ossifications, another complication of obscure nature.

In general, no significant correlation was found between the level of the lesion and the skeletal abnormalities. In patients with lumbar lesions and hydronephrosis, however, there was a somewhat accelerated course of sacro-iliac changes. It is possible that this finding is related to a low motor neuron lesion of the urinary tract.

\section{Conclusions}

(1) 113 patients with cervical (48), dorsal (35), and lumbar (30) spinal cord lesions were examined from the point of view of:

(a) $X$-ray changes in the sacro-iliac joints.

(b) Presence of abnormal excretory urograms.

(c) Duration of illness.

(2) Radiologically abnormal sacro-iliac joints were present in 58 per cent. of the whole group, with a slightly lower incidence in patients with dorsal as compared to those with cervical and lumbar lesions.

(3) The incidence of sacro-iliac changes was the same in patients with abnormal and normal excretory urograms (62 and 63 per cent. respectively); after follow-up of more than 5 years these percentages became respectively 52 and 72 per cent.

(4) Analysis of physiologically complete lesions of the spinal cord shows a characteristic time course of sacro-iliac changes, these are slight during the first 2 years after injury, and then show a rapid increase followed by a slow progression, the final stage being reached in most cases after 7 to 8 years.

(5) The course of the skeletal changes is the same whether the excretory urogram is normal or abnormal except for the lumbar lesions; in this case patients with hydronephrosis show a slightly accelerated course of joint changes.
(6) There is no evidence that urinary infection per se is a dominant factor in the genesis of skeletal changes. Other factors, possibly genetic, may intervene, as some patients develop no skeletal changes 10 years or more after injury.

(7) There is no significant evidence that the level of the lesion per se is the dominant factor in the genesis of the skeletal changes.

\section{Summary}

Correlation between sacro-iliac changes and urinary infection was evaluated in a group of 113 quadriplegics and paraplegics. Significant urinary infection manifested by persistent hydronephrosis per se does not appear to be a dominant factor in the genesis of skeletal $x$-ray changes. These occur independently of the urinary complications and regardless of the level of transsection of the cord. Other factors, possibly genetic, may intervene, as some patients with or without excretory urogram abnormalities do not develop sacro-iliac changes.

\section{REFERENCES}

Abramson, D. J., and Kamberg, S. (1949). J. Bone Jt Surg., 31-A, 275

Alexander, C. (1960). N. Z. med. J., 59, 320.

Good, A. E. (1962). Ann. intern. Med., 57, 44.

Grainger, R. G. and Nicol, C. S. (1959). Brit. J. vener. Dis., 35, 92.

Liberson, M. (1953). J. Amer. med. Ass. 152, 1010.

Oates, J. K. (1959). Brit. J. vener. Dis., 35, 81.

Poske, R. M., Montgomery, M. M., Pilz, C. G., Barton, E. M., and Foxworthy, D. T. (1961). Arthr. and Rheum., 4, 432 (Abstr.).

Romanus, R. (1953). Acta med. scand., Suppl. 280.

Changements sacro-iliaques et l'infection urinaire chez les malades atteints de lésions traumatiques de la moelle épinière

RÉSUMÉ

La corrélation entre les changements sacro-iliaques et l'infection urinaire a été évaluée chez un groupe de 113 quadriplégiques et paraplégiques. Une infection urinaire marquée se manifestant par une hydronéphrose persistante per se ne semble pas être un facteur important dans la genèse des changements du squelette vus aux rayons $X$. Ces changements ont lieu indépendamment des complications urinaires et aussi sans se soucier du niveau de section de la moelle épinière. D'autres facteurs, possiblement d'ordre génétique, peuvent intervenir car certains malades avec ou sans anomalies excrétoires à l'urographie ne développent pas de changements sacro-iliaques. 